\title{
ECONOMETRIC ANALYSIS OF LOGISTICS AND TRANSPORTATION SPENDING AND EXPORT IN TURKEY
}

\author{
DOI: 10.17261/Pressacademia.2020.1211 \\ JEFA- V.7-ISS.2-2020(8)-p.166-172
}

Beyhan Incekara

Istanbul Kent University, Faculty of Humanities and Social Sciences, Department of International Trade and Logistics, Istanbul, Turkey. beyhan.incekara@kent.edu.tr ,ORCID: 0000-0002-4937-0868

To cite this document

Incekara, B., (2020). Econometric analysis of logistics and transportation spending and export in Turkey. Journal of Economics, Finance and Accounting (JEFA), V.7(2), p.166-172.

Permanent link to this document: http://doi.org/10.17261/Pressacademia.2020.1211

Copyright: Published by PressAcademia and limited licensed re-use rights only.

\begin{abstract}
Purpose- The aim of this study is to examine the role of transport expenditures in increasing the export and correcting its composition by examining the relationship between transport expenditures and export, which are the cornerstones of the logistics sector, with an econometric analysis.

Methodology- While analyzing the logistics sector, since the numerical data sources are not sufficient, transportation expenditure data, which is the most important item of the logistics sector, was used. In this study, the relationship between transportation expenditures and exports, which constitute the most important share in logistics sector, was found by applying Granger Causality Tests and Toda and Yamamoto econometric model.

Findings - The relationship between transportation expenditures and exports in the study was applied to Granger Causality Tests and Toda and Yamamoto econometric model. As a result, a two-way causality relationship has emerged between transportation expenditures and exports. The increase in exports will cause countries to expand and diversify their transportation channels in order to export more.

Conclusion- As revealed in the study; accelerating export will accelerate newer methods and new transportation routes, and export and logistics - transportation will feed each other. Further reduction of transportation and transportation costs depends on the use of modern systems and good management of the supply chain. Exports will increase when the logistics structure is well established, and more multimodal transportation systems and logistics networks will be expected as exports increases.
\end{abstract}

Keywords: Logistics, export, transportation, Granger Causality Tests, Toda and Yamamato Econometric Model.

JEL Codes: E00, F00, R40

\section{TÜRKIYE'DE LOJISTIK VE ULAŞTIRMA HARCAMALARI VE IHRACAT ILIŞKISININ EKONOMETRIK ANALIZi}

\section{ÖZET}

Amaç- Bu çalışmanın amacı; ihracat hacminin arttırılabilmesi ve kompozisyonunun düzeltilebilmesi için lojistik sektörünün temel taşlarından olan ulaștırma harcamaları ve ihracatın ilișkisinin ekonometrik bir analizle incelenerek, ulaștırma harcamalarının öneminin belirlenmesidir. Yöntem- Bu çalışmada, lojistik sektöründe en önemli payı oluşturan ulaştırma harcamaları ve ihracat arasındaki ilişkinin incelenmesinde Granger Nedensellik Testleri ile Toda ve Yamamoto ekonometrik modeli kullanılmıştır.

Bulgular- Çalışma sonucunda, "Ulaştırma harcamaları ve ihracat arasındaki ilişkinin araştııılığı, çalışma sonucunda değişkenler arasında çift yönlü nedensellik ilişkisi tespit edilmiştir." İhracattaki artış -ülkeleri daha fazla ihracat yapabilmek için- ulaşım kanallarını genişletmesine ve çeşitlendirmesine yöneltecektir.

Sonuç- Artan ihracatta yeni yöntemler, yeni ulaştırma yollarını hızlandıracak ve ihracat ve lojistik - ulaştırma birbirini besleyecektir. Taşımacılık ve ulaştırma maliyetlerinin aşağıya çekilmesi, modern sistemlerin kullanılmasına ve tedarik zincirinin iyi yönetilmesine bağlıdır. Lojistik yapısı iyi oluştuğunda ihracat artacak, ihracat arttıkça da daha multimodal taşımacılık sistemleri ve lojistik ağı oluşacaktır.

Anahtar Kelimeler: Lojistik, ihracat, ulaştırma, Granger Nedensellik Testleri, Toda ve Yamamato Ekonometrik Modeli JEL Kodları: E00, F00, R40 


\section{GiRiş}

2018 yılında ABD ve Çin arasında başlayan ticaret savaşları tüm dünya ekonomisi gibi Türkiye'yi de etkilemiştir ve etkileri hâlen devam etmektedir. Dünya ekonomisi serbest ticaret hacminden engelli ve korumacı ticaret uygulamalarına geçmekte olup birbiriyle ticaret partnerliği yapan tüm ülkelerin birbirini etkilemesi durumu ortaya çıkmıştır. Türkiye için ithalatta ilk sırada yer alan Çin'e uygulanan yaptırımlar önemli ölçüde etki yaratmaktadır. Buna ilave olarak ihracat açısından birinci sırada Almanya ikinci sırada İngiltere üçüncü sırada İtalya bulunmaktadır. Ticaret savaşlarında ABD tarafında yaptırımlardan en çok etkilenen bölge Euro Zone (Avrupa Birliği) olduğundan bu bölgedeki ticaret hacmi daralması Türkiye'yi de etkilemektedir. İste tüm bunlar ışığında kurlardaki hareketlilik de göz önüne alındığında Türkiye ihracat hacmini arttırmakta ve yaptırımların etkisini en aza indirgemeye çalışmaktadır. İhracat 2019 Ekim ayı itibariyle ihracat, 16 milyar 336 milyon dolar olarak gerçekleşmiştir.

İhracatın kompozisyonuna baktığımızda ara malı ve hammadde ithalatının hala yüksek olduğu görülmekte ve bunların ithali yerine üretim yapıldığında ihracatın daha fazla katma değer yaratacağı ortaya çıkmaktadır.

Buna ilave olarak son ihracat rakamlarında payı artsa da yüksek nitelikli işgücü yetiştirerek yüksek katma değerli daha çok döviz kazanacağımız stratejik, teknoloji içeren ürün ihracatını daha da arttırmak önemli konulardan birisi olarak karşımıza çıkmaktadır.

İhracatın artarken ve kompozisyonu değişirken ihracatın en önemli ayağı lojistik sektörü olarak karşımıza çıkmaktadır. Türkiye'de ve dünyada özellikle e-ticaret artarken perakendecilikten online satışlara doğru bir eksen kayması olduğu için zaten önemli olan lojistik sektörü daha da önemli hâle gelmiştir. Çünkü ihracatın zamanında yapılması, ürünün güveli ve konforlu taşınması ve bunun minimum maliyetle taşınması lojistik sektörü ile mümkün olmaktadır. 2023 hedefleriyle Türkiye, dünyanın en büyük 10 ekonomisinden birisi olmayı hedeflemektedir. Bu hedeflemede bazı sektörler ön plana çıkmaktadır. Türkiye'nin ekonomik anlamda güçlenmesini sağlayacak en önemli sektörlerden birisi de lojistik sektörüdür.

21. yüzyılın başlarında, Türkiye'de lojistik sektörü, emekleme dönemini geride bırakmıştır. Ulusal ve uluslararası firmalarla işbirliğine giden, yurtdışında bürolar açan, vermiş olduğu hizmetlerin kalitesini arttıran, sürekli gelişen dinamik bir sektör haline gelmiştir. (Daşkan, 2016; 39). Bu sektörde son zamanlardan ciddi gelişmeler yaşayan Türkiye, coğrafi üstünlükleriyle ve dünya ekonomisi açısından stratejik konumu sayesinde lojistik üs ve transit ticaret merkezi olma potansiyeli taşımaktadır. Lojistik sektörü incelenirken, lojistik hizmetinin sağlandığı demiryolları, havayolları, karayolları ve deniz yolları etkinliği ve gelişmişliği önem kazanmaktadır. Çünkü iyi bir lojistik sistemi güçlü ve gelişmiş demiryolları, havayolları, karayolları ve deniz yolları ile mümkün olmaktadır. Lojistik sektöründe, firmalar arası işbirliklerinin artması Türkiye'deki firmaların uluslararası firmalar ile karşışlaştırıldığında mali açıdan daha dezavantajlı noktada olduğunu göstermektedir (Koban ve Keser, 2008; 88).

Uluslararası arenada rekabet edebilirliği etkileyen en önemli unsur maliyetleridir. Bu maliyetlerde, hangi ürünün taşındığına, nereye taşındığına ve hangi ulaştırma moduyla taşındığına bağlıdır. Mesela; Karayolu yük taşımacılığında kamyon, çekici ve yakıt, demiryolunda lokomotif ve vagon, denizyolunda gemi, antrepo havayolunda uçak ve işletme maliyetleri gibi birçok maliyet kalemi bulunmaktadır. Nakliye hizmetlerinin fiyatlandırılması noktasında, amortisman ve bakım, iş̧̧ilik, yakıt, malzeme ve genel giderler firmaların mali kurgusunu oluştururken görmesi gereken temel öğeler olaran göze çarpmaktadır. (Demir, 2008; 25).

Lojistik sektörü maliyetleri ve gelişimi içerisinde en önemli unsur, kuşkusuz ki kamunun da içinde yer aldığı ulaştırma harcamalarıdır. Ulaştırma harcamaları içinde en büyük pay ulaştırma yatırımlarınındır ama buna ilave olarak yapılan çeşitli ulaşım ve lojistik faaliyetleri, gümrük ve liman harcamaları da bu kapsama girmektedir. Bu bağlamda ulaştırma gelirleri ve giderleri dış ticaretin ihracatın belirleyicisidir. Türkiye'de ulaştırma harcamaları incelendiğinde; yük taşımacılı̆ıında en çok karayolu ulaştırması görülmektedir, bunu sırasıyla denizyolu taşımacılığı, demiryolu ve havayolu takip etmektedir. Oysaki denizyolu, en düşük maliyet ve en çok yük taşıma kapasitesine sahip seçenektir. Ancak "door to door" özelliği nedeniyle daha maliyetli olmasına karşın- karayolu taşımacılı̆̆ tercih edilmektedir. Ulaştırma harcamaları özellikle 2002 yılından sonra artış göstermiş̧ir, özellikle 2014-2015 döneminde \%37 ile harcama kalemleri arasında en üst seviyeye ulaşmıştır. Sonrasında yaşanan kur dalgalanmaları ile birlikte ticaret hacminde meydana gelen azalış, ulaştırma harcamalarına da yansımıştır; uygulanan sıkı para ve maliye politikalarıyla oranı azalmıştır. Ama yine de -ihracat için birinci öncelikli koşullardan olması sebebiyle- ulaştırma harcamalarının gelişimi ve çeşitlendirilmesi devam etmektedir. 
Türkiye'nin jeopolitik fırsatları ve transit geçiş yollarında bulunması, özellikle devreye girecek olan Yeni İpek Yolu Projesi gibi projelerle lojistik üs olması, ulaştırma harcamalarını yönlendirerek ihracatı daha da hızlandırması öngörülmektedir.

Dış ticarette lojistik sektörünün yeri oldukça önemlidir. İthal veya ihraç edilen tüm ürünler lojistik hizmetlere konu olmaktadır. Dolayısıyla ithalat-ihracat ve lojistik, -özellikle de taşımacılık-, arasında bir ilişki olduğu ve bu ilişkinin de dolaylı olarak ülkenin uluslararası ticaretine yansıdığı görülmektedir. Uluslararası ticaretin serbestleşmesiyle ve teknolojinin ilerlemesiyle yeni stoklama ve depolama teknikleriyle lojistik önemli ölçüde gelişmiştir. Lojistik boyutundaki modern depolama, stoklama, pazarlama, ambalajlama alanları hem maliyetler açısından avantaj sağlamaktadır. Hem de ürünün pazarlara daha güvenli ve hızlı ulaşmasında olumlu rol oynamaktadır.

İhracat ve lojistik sektörünün teorik ilişkisine bakıldığında; çalışma sonuçları ile de ampirik olarak tespit edilen çift yönlü nedensellik ilişkisi görülmektedir.

i. Ihracat açısından; özellikle son yıllarda ülkelerarası ticaret hacminin artmasıyla ve döviz kazandırıcı etkileri sebebiyle ihracatın artması lojistik sektörünün de hızlanmasına, daha modern yöntemlerin kullanılmasına ve yeni ulaştırma yolları açılmasına vesile olmuştur. Daha kısa, daha güvenli ve daha az maliyet oluşturacak yollar yapılmış, genişletilmiş ve revize edilmiştir. Bunun yanı sıra karayolu, havayolu, denizyolu ve demiryolu olarak ulaştırma modlarına daha çok harcama yapılması söz konusu olmuştur. Örneğin mega projelerden olan İstanbul Havalimanı Projesi ile hava kargo taşımacılığı ve Türkiye'nin lojistik üs olmasına katkıda bulunulacak ulaştırma harcamaları gerçekleşmiştir. Ayrıca karayollarında genişletmeler, yeni yollar ve Osmangazi Köprüsü gibi köprülerin açılması, demiryollarında yeni yük vagonları ve güzergahları ve denizyolunda da liman ve antrepo düzenlemeleri yapılmıştır. İhracatın artması yeni pazarlara açılma için ulaştırma ve lojistik alanında yeni ve olumlu hamlelerin ortaya çıkışını sağlamıştır. Dış ticaretin gelişimi ve lojistiğin gelişimi birlikte ilerlemektedir. Bunun nedenlerini özetleyecek olursak (Tunç ve Kaya, 2016:60):

- Uluslararası ticaretin gelişmesiyle beraber kıtalararası ticaret de gelişmektedir. Bu açıdan, denizyolu taşımacılığının da doğal olarak gelişmesini sağlamaktadır. Denizyolu taşımacılığının, lojistikte diğer ulaştırma modlarına göre daha çok teknoloji kullanımına sahip olduğunu da unutmamak gerekir.

- Uluslararası ticaretin gelişmesiyle beraber "lojistik" bir sektör haline gelmiştir. Bu durum kalifiye beşeri sermaye intiyacını da belirginleştirmiştir. Ülkeler de bu ihtiyacın giderilmesine yönelik olarak, lojistikle ilgili yükseköğretim alanları açmaya başlamıştır.

- $\quad$ Uluslararası ticaretin gelişmesiyle beraber, limancılık faaliyetleri ve konteynır taşımacılığı de gelişmiştir. Bu durum lojistiğin gelişmesine katkı sağlamıştır.

ii. Lojistik sektörü; lojistik sektörü ve ulaştırma harcamaları da arttıkça daha fazla ihracat miktarı gerçekleşmektedir. Özellikle Yeni İpek Yolu Projesine bakıldı̆̆ında; birçok taşıma modu kullanılarak multimodal ulaştırma sistemleri kullanıldığından yükün taşınması çok daha entegre ve daha az maliyetli olacaktır. Transit bölge avantajı bulunan Türkiye ulaştırma modlarını geliştirerek çok daha önemli gelirler elde edecektir. Yani gelişmiş ticaret ağları, multimodal taşımacılık ile ihracat daha da artmaktadır.

Pazar- Tedarik- Lojistik- ihracat aşamaları birbirini besleyen her bir aşamadaki iyileşme, ihracatı arttıran bir faktör olarak karşımıza çıkmaktadır. Yeni pazarlar tedarik zincirinin sorunsuz ilerlemesi, lojistik sektörünün işleyişini hızlandırır, bu da ihracatı arttırmaktadır. İhracat- Lojistik- Tedarik- Pazar sıralaması ile ihracattan lojistiğe doğru bakacak olursak; ihracatın artışı gerek yeni pazarlara gerekse de mevcut pazarlara daha hızlı yükleri ulaştırma için lojistik sektörüne devredilmekte oradaki yük taşımacılığı sistemine uygun bir şekilde tedarikçiye oradan da pazara ulaşmaktadır. Yani artan ihracat, var olan ulaştırma ağlarını ve lojistik sektörünü hem kamu hem de özel sektörün desteğiyle geliştirmektedir. Çünkü ihracat yapabilmek için tüm ulaştırma sistemi ve akabinde lojistik sektörü organize olarak hareket etmelidir.

Bu çalışma daha önce lojistik ve ulaştırma harcamaları ile ihracat arasındaki ilişkiyi bu yöntemle inceleyen herhangi bir eser olmaması nedeniyle literatüre katkıda bulunmuştur. Çalışmanın birinci bölümünde Türkiye'de lojistik sektörü analiz edilmiş olup lojistiği besleyen en önemli unsur olan ulaştırma harcamaları incelenmiştir. Bununla birlikte Türkiye'nin ihracat kompozisyonu ve maliyet unsurlarına değinilmiştir. İkinci bölümde ulaştırma ve ihracat ilişkisi incelenmiş olup sonraki bölümde uygulanan yöntemle ilgili bilgiler, analizin bulguları ve sonuçlara değinilmiştir. 


\section{LITERATÜR ÖZETi}

Konuya ilişkin birçok ülkede değişik formlarda çalışmalar yapılmıştır. Bunlardan bazıları şu şekilde belirtilmiştir:

Lojistik, bir ülkenin gelişiminde çok önemli bir rol oynar. Ulaşım ise etkili ve başarılı bir şekilde sürdürülen lojistik sisteminin bel kemiğidir. Ulaşım, lojistik maliyetinin önemli bir bölümünü teşkil eder. Ulaşım sistemi ile ekonominin önemli sektörleri arasında doğrudan veya dolaylı bağlantılar vardır. Ulaşım altyapısı boyutu ülkelerin ekonomik kalkınmalarını etkiler.

Choudhary, Khan, Muhammad ve Abbas (2009), verimli ve kaliteli dizayn edilmiş bir ulaşım sistemi, üretim maliyetini azaltarak ekonomik büyümeyi arttırmaktadır. Ulaşım sistemlerinin etkinliği ve kullanışlılı̆ı, firmaların üretim kapasitesini pozitif yönde etkilemektedir.

Larch 2007, Doğu Avrupa'daki Ülkeler ile Kıta Avrupa'daki Ülkeler 1990 - 2002 Doğrudan Yabacı Yatırımların Yeni Ticaret Modeliyle Ulaşım Sektörünü nasıl etkilediğini ve etkinliğini nasıl arttırdığını incelemektedir. Ulaşım Sektörü ise Milli Gelir ve Ticaret Hacmini arttırmıştır. Bu etkiler de Kıta Avrupasında ve Doğu Avrupa'da yer alan ülkelerin büyümesine olumlu etkide buunmaktadır.

Akbulut ve Sekmen (2015), çalışmasında ulaşım maliyetlerinin uluslararası ticaret üzerindeki etkisini analiz etmektedir. Ampirik çalışmanın sonuçlarına göre, ulaşım maliyeti ile uluslararası ticaret arasında ters yönlü bir ilişki tespit edilmiştir. Ulaştırma maliyetlerinin artması, firmaların daha yüksek bir maliyete katlanması nedeniyle uluslararası ticareti azaltmaktadır. Firmaların katlanmak zorunda oldukları maliyetler caydırıcı bir etki yaratmaktadır.

Liping Zhu, Xubiao Yang (2011), çalışmasında nedensellik Analizini uygulayarak uluslararası ticaret ve ulaştırma arasında çift taraflı nedensellik tespit edilmiştir. Birbirleriyle iç içe geçen uluslararası ticaret ve ulaştırma karşılıklı bağımlıık gösterir. Gelişmiş bir ulaştırma ağı, bir uluslararası ticareti getirirken, uluslararası ticaretin artışı yeni ulaştırma ağlarını beraberinde getirmektedir.

Hou Fang-Miao (2008), çalışmasında lojistik ve dış ticaret arasındaki ilişkiyi incelemiştir. Etkileşim analizini kullanarak uyguladığı çalışmada lojistiğin dış ticareti etkilemesi, dış ticaretin lojistiği etkilemesinden daha belirgindir sonucuna ulaşmıştır. Lojistik ağının genişlemesi, etkinliği ve verimliliği, dış ticareti pozitif yönlü etkilemektedir. Dış ticaretin artışı ise lojistik ağına daha az etkide etkide bulunmaktadır.

Chu Zhao-Fang, Wang Qiang (2010), çalışmasında ilişki analizi çerçevesinde, uluslararası ticaretteki inovasyonun, havayolu taşımacılı̆ına pozitif yönde bir etki yarattığını incelemiştir. İnovasyon çalışmaları, değişen ve gelişen teknoloji ile uluslararası ticaret, havayolu taşımacılığını pozitif yönlü etkilemiştir.

Zhang Bao-You (2009), duyarlılık analizi metodu ile, ülkelerin lojistik anlamında gelişiminin, uluslararası ticareti olumlu yönde etkilediği sonucuna ulaşmışlardır. Lojistik yatırımlarının artışı ile lojistik ağının genişlemesi, uluslararası ticareti pozitif yönde etkiler. Taşıma modları ve ulaştırma ağının kullanışlığı ve etkinliği dış ticarete yönelen firmaları ve ülkeleri de tetiklemektedir.

Yang Chang-Chun (2008), ilişki analizi çerçevesinde, lojistik ile uluslararası ticaret arasında ortak bir hareketin olduğunu, uluslararası ticaretin lojistiğe daha çok katkı verdiği sonucunu ortaya çıkarmışlardır. Uluslararası ticaretle ilgilenen firmaların artışı, ülkelerin artan küreselleşme "global bir köy" haline dönen dünyada uluslararası ticarette rekabete girişmesi, lojistik ağının da gelişmesini sağlamıştır.

Wang li-Jun (2005), etkileşim analizi metoduyle, uluslarararası ticaretin gelişimi için küresel lojistiğin gelişmesi kaçınılmazdır sonucuna varmışlardır. Yani ülkelerarası dış ticaretin gelişimi lojistik süreçleriyle yakından ilgilidir. Birbirini tamamlayan ikili uluslararası ticaret ve lojistik, süreçler noktasında da etkileşimdedir. Uluslararası ticaret ve lojistik süreçleri çift yönlü etkili iki sektördür

Tunç ve Kaya (2016), nedensellik ilişkisi çerçevesinde, lojistik ile uluslararası ticaret arasında çift yönlü ilişki tespit edilmiştir. Yani lojistik faaliyeti arttıkça uluslararası ticaret, uluslararası ticaret arttıkça lojistik faaliyetleri de artmaktadır. Uluslararası ticaret ve lojistik faaliyetlerin gelişmesi ile çift kaldıraç etkisi ortaya çıkmaktadır. Birbirini besleyen iki sektörde yaşanan gelişmeler ekonomiye pozitif yönlü etki doğurmaktadır.

\section{METEDOLOJi, VERI VE AMPIRIK SONUÇLAR}

Çalışmada kurulacak ekonometrik model ile lojistik sektörü ve ulaştırma harcamaları ve ihracat arasında ilişki olup olmadığı araştırılacaktır. Lojistik sektörüne ait detaylı ve sağlıklı rakamsal veriler bulunmadığı için ulaştırma harcamaları veri olarak kullanılacaktır. Çünkü ulaştırma ve lojistik iç içe geçmiş birbirini tamamen etkileyen faktörlerdir. 
Yapılan çalışmada ulaştırma harcamaları (ULH) ile ihracat (IHR) arasındaki ilişki incelenmiş ve 1960-2018 arasındaki dönemi kapsayan yıllık veriler kullanıımıştır. İhracat verilerine TÜiK'den, ulaştırma harcamalarına ise Hazine ve Maliye Bakanlığı web sitesinden (www.bumko.gov.tr)'ndan ulaşılmıştır.

Modelin bilgisayar uygulaması için E-views 10.0 programı ile çalışıımıştır. Analizde kullanılan değişkenlere ait tanımlayıCı istatistikler Tablo 2'de sunulmuştur.

Bu çalışmada ulaştırma harcamaları ile ihracat arasındaki ilişkinin nedensellik boyutunu incelemek için Toda ve Yamamoto tarafından 1995 yılında geliştirilen Toda-Yamamoto nedensellik testi tercih edilmiştir. Bu testin seçilmesinde birden çok avantajlı durumun olması etkili rol oynamıştır. Bunlardan biri Granger nedensellik testlerini araştırma hedefiyle geliştirilmiş VAR modelini tahmin etmek için çok daha basit bir yol sunmasıdır(Granger,1988).

Toda ve Yamamoto (1995) tarafından kısa dönem analizi olarak ortaya atılan bu yöntemin, seriler arası koentegre ilişkiden bağımsız bir şekilde VAR model üzerinden nedensellik bulgularına olanak sağlaması da başka bir avantajlı yönü olarak görülmektedir.

Toda-Yamamoto testinde, Granger nedensellik testi gibi serilerin aynı mertebeden durağan olma şartı aranmamaktadır. Farklı mertebelere sahip seriler arasında da nedensellik analizi yapılabileceğini gösteren Toda-Yamamoto testi, seriler hangi mertebede durağan olursa olsun düzey değerlerini kullanılarak VAR model oluşturmaktadır. İki aşamadan oluşan bu testte öncelikle optimal gecikme uzunluğu belirlenmekte ve uygulamaya konu olan seriler için maksimum bütünleşme derecesi (dmax) tespit edilmektedir. VAR model için uygun gecikme uzunluğunun saptanması, Akaike ve Hannan-Quinn gibi kriterler kullanılarak yapılmaktadır. Böylece optimal gecikme uzunluğu k ile maksimum bütünleşme derecesi dmax ın tespiti ile beraber $k+d m a x$ gecikme uzunluğunu barındıran geliştirilmiş VAR modeli tahmin edilmektedir. íkinci aşamada ise elde edilen $k$ gecikmeli VAR katsayı matrisine Wald testleri uygulanmakta ve sonucunda Granger nedenselliğe bağlı çıkarımlar yapılabilmektedir.

İlk olarak değişkenlerin durağanlık mertebelerinin belirlenmesi amacıyla Genişletilmiş Dickey-Fuller (ADF) birim kök testi kullanılmıştır. Değişkenlerin düzeylerine ve farklarına ait ADF birim kök testlerinin sonuçları aşağıdaki tabloda sunulmuştur( Dickey and Fuller,1979).

Tablo 2: Tanımlayıcı İstatistikler

\begin{tabular}{lcc}
\hline & IHR & UHL \\
\hline Ortalama & 229000000 & 330000000000 \\
Medyan & 24009171 & 806992 \\
Maksimum & 876000000 & 3670000000000 \\
Minimum & 73470.39 & 1.12 \\
Standart Sapma & 294000000 & 712000000000 \\
Çarpıklık & 0.774196 & 2.820589 \\
Basıklık & 1.86494 & 11.60584 \\
Gözlem Sayısı & 59 & 59 \\
\hline \hline
\end{tabular}

Tablo 3: Değişkenlerin Düzeylerine ve Farklarına ait ADF Birim Kök Testi Sonuçları

\begin{tabular}{ccc}
\hline \multicolumn{3}{c}{ Genişletilmiş Dickey-Fuller (ADF) Birim Kök Testi } \\
\hline Değişkenler & Gecikme Uzunluğu & t-istatistiği \\
\hline ULH & 9 & $-6.007390^{*}$ \\
IHR & 0 & -0.634221 \\
SIHR & 1 & $-6.252997^{*}$ \\
\hline \hline
\end{tabular}

* \%5, anlamlılık düzeyinde sıfır hipotezi olan birim kökün varlığııın reddedildiğini göstermektedir. Gecikme uzunlukları Akaike Bilgi Kriteri (AIC) kullanılarak belirlenmiştir. " $\Delta$ " serilerin 1.farkının alındığını belirtmektedir. 
Tablo 3'ün sonuçlarına göre ulaştırma harcamaları değişkeni düzeyde I(0) durağan iken ihracat değişkeni birinci farkında durağan olarak belirlenmiştir. Toda-Yamamoto nedensellik testi için değişkenlerin düzey değerlerinin aynı mertebede olmasına gerek duyulmadığından ötürü düzey değerlerle kurulan modellerin çalışmaya uyarlanmış hali aşağıdaki gibidir:

$$
\begin{gathered}
U L H_{t}=\alpha_{1}+\sum_{i=1}^{k+d \max } \beta_{1 i} I H R_{t-i}+\sum_{i=1}^{k+d \max } \theta_{1 i} U L H_{t-i}+\varepsilon_{1 t} \\
I H R_{t}=\alpha_{2}+\sum_{i=1}^{k+d \max } \beta_{2 i} U L H_{t-i}+\sum_{i=1}^{k+d \max } \theta_{2 i} I H R_{t-i}+\varepsilon_{2 t}
\end{gathered}
$$

Buna göre $k$, VAR model yardımıyla " 5 " olarak, dmax ise "1" olarak belirlenmiş ve genişletilmiş VAR(2) modeli görünüşte ilişkisiz regresyon yöntemi ile tahmin edilmiştir. Bu model yardımıyla elde edilen nedensellik analizi sonuçları Tablo 2'de gösterilmiştir.

Tablo 4: Toda-Yamamoto Nedensellik Analizi Sonuçları

\begin{tabular}{ccc}
\hline Sıfır Hipotezi & Gecikme Uzunluğu & MWALD İstatistiği \\
\hline $\boldsymbol{I H} \boldsymbol{R} \leftrightarrow \boldsymbol{U L H}$ & 6 & $670.51^{*}$ \\
$\boldsymbol{U} \boldsymbol{L H} \leftrightarrow \boldsymbol{I H} \boldsymbol{R}$ & 6 & $30.67^{*}$ \\
\hline \hline
\end{tabular}

* \%5 anlamlılık düzeyinde sıfır hipotezinin reddedildiğini göstermektedir.

Tablo 4'ün sonuçlarına göre kısa dönemde ihracat ve ulaştırma harcamaları arasında çift yönlü nedensellik ilişkisine rastlanılmıştır.

Teorik olarak belirtildiği gibi, ulaştırma harcamaları yani lojistik sektörüyle ihracat arasında çift yönlü etkileşim vardır. İhracattaki artış ülkeleri ulaşım ağlarını genişletme ve çeşitlendirme yönünde çalışmalar yapmalarını gerektirmiştir. Özellikle de ihracatın artması yeni pazarlara ulaşmada hem ulaşım sistemlerinin hem de lojistik faaliyetlerin hızlanması ve modernleşmesini sağlamaktadır. Diğer tarafta da modernleşen ve dünyadaki lojistik trendlerine uygun depolanan, stoklanan ve taşınan yükler ihracatın artış hızını daha da arttırmıştır. Lojistik hizmetlerindeki artış ihracatın çeşitlenmesini ve sınır ötesine geçişini kolaylaştırmaktadır.

\section{SONUÇ}

Türkiye jeopolitik konumu gereği önemli ticaret yolları üzerinde yer almasıyla tarih boyunca en yoğun ticari işbirlikleri yaşamıştır. Bu sebeple lojistik sektörünün ülke ekonomisi ve uluslararası ticaret üzerinde etkisi oldukça fazladır. Lojistik sektörünün gelişimi, dış ticaretin -özellikle de döviz kazandırıı tarafı olan- ihracatın gelişimine katkıda bulunmaktadır. Türkiye'nin uluslararası arenada rekabet edebilirliğini ve Pazar payını koruyabilmesi için güçlü ulaştırma ağlarına ve lojistik sektörüne ihtiyacı vardır. Türkiye'de dış ticaret ve lojistik sektörü birbiri ile iç içe girmiş, tamamlayıcı nitelikte yapılardır.

Dünyada olduğu gibi Türkiye'de de lojistik hizmetlerinde gelişmiş teknolojilerin kullanılması hız kazanmaya başlanmıştır. Özellikle modern depolama faaliyetleri, stoklama veya elleçlemede uygulanan yeni yöntemler, yüklerin daha dayanıklı ve güvenli bir şekilde ulaştırılması için ambalajlama teknikleri ve yüklerin kontrolünü sağlayan bilgi teknolojileri her geçen gün daha çok kullanılmaktadır. Bununla birlikte intermodal taşımacılık türlerinin kullanımı denizyolu taşımacılığı ile gelen yüklerin karayolu ilave edilerek istenilen bölgeye direkt ulaştırılması gibi birçok lojistik faaliyet yük taşınmasındaki hızı arttırmaktadır. Tedarikçilerin çeşitlendirilmesi, uygun ulaştırma modunun kullanılması, taşımacılık hızını da arttıracak ve bu da ihracatı hızlandıracaktır.

Çalışmada uygulanan ampirik sonuçlarında desteklediği gibi ihracat ve ulaştırma harcamaları arasında çift yönlü nedensellik ilişkisine rastlanılmıştır. Ulaştırma ve lojistik ilişkisi e-ticaret ile birbirini daha da desteklemekte ve ihracatı da hızlandırmaktadır. Çünkü ihracatın en önemli aşamaları lojistiğin ve ulaştırmanıın sağlandığı aşamalardır. Buna ilave olarak ihracatın dijitalleşmesiyle lojistik ve ulaştırmada da dönüşüm yaşanmaktadır. Çalışmada tespit edildiği üzere; hızlanan ihracatta daha yeni yöntemler, yeni ulaştırma yollarını hızlandıracak ve ihracat- lojistik - ulaştırma birbirini besleyecektir. Daha önce lojistik ve ulaştırma harcamaları ile ihracat arasındaki ilişkiyi bu yöntemle inceleyen herhangi bir çalışma olmaması nedeniyle literatüre katkıda bulunmuştur. 
Küreselleşmeyle ve son dönemdeki teknolojik gelişmelerle artan ürün çeşitliliği, pazar payı ve ülke sınırlarını aşan uluslararası ticaret hacmi ihracatı daha da önemli hâle getirmekte ve ihracatı yaparken elde edilen döviz geliri ülkelerin cari dengeleri için önemli olduğundan maliyet kalemleri daha detaylı incelenmektedir. Maliyet kalemleri içerisinde taşımacılık maliyetleri dikkat çekmektedir. Taşımacılık ve ulaştırma maliyetlerinin daha da aşağıya çekilmesi modern sistemlerin kullanılmasına ve tedarik zincirinin iyi yönetilmesine bağlıdır. Lojistik yapısı iyi oluştuğunda ihracat artacak, ihracat arttıkça da daha multimodal taşımacılık sistemleri ve lojistik ağı oluşması beklenmektedir.

\section{KAYNAKÇA}

Akbulut G. ve Sekmen O., (2015), Uluslararası Ticaretin Gelişmesinde Ulaşım Maliyetlerinin Rolü:Türkiye Örneği, Balkan and Near Eastern Journal of Social Sciences Balkan ve Yakın Doğu Sosyal Bilimler Dergisi, 01 (01): 20-29.

Chouhary, Muhammad; Khan, Nawar; Arshad, Muhammad and Aisha Abbas (2009), Analyzing Pakistan's Freight Transportation Infrastructure Using Porter's Framework and Forecasting Future Freight Demand Using Time Series Models, Proceedings of the 2nd Wseas International Conference on Urban Planning and Transportation, 70-77.

Daşkan E.S. (2016), Türkiye'de Lojistik Hizmetlerdeki Gelişimin Dış Ticaret Üzerine Yansımaları, İstanbul Ticaret Üniversitesi Dış Ticaret Enstitüsü, Yüksek Lisans Tezi.

Demir, V. (2008). Lojistik Yönetim Sisteminde Maliyet Hesaplama (2. Baskı.). Ankara: Nobel Basım Evi.

Dickey, D.A. ve W.A. Fuller (1979), Distribution of the estimators for autoregressive time series with a unit root, Journal of the American Statistical Association, 74, 427-431.

Granger, C.W.J. (1988). Some Recent Development in a Concept of Causality. Journal of Econometrics, 39, 199-211.

Hou, F. (2008). Modern Logistics: Accelerator of International Trade, Finance \& Economics, 4, 13-20.

Koban, E. ve Keser, H. Y. (2008). Dış Ticarette Lojistik (2. Baskı). Bursa: Ekin Yayınları.

Larch, Mario; (2007), The Multinationalization of the transport sector, Journal of Policy Modeling, 29(3):397-416.

Liping Zhu, Xubiao Yang (2011), Study on the relationship between Shanghai air logistics and international trade, Journal of System and Management Sciences, 1(2):69.

TCMB, Hazine Ve Maliye Bakanalığı, TUiK, Strateji ve Bütçe Başkanlığı, 2018 ve 2019 P. 2019 Yılı Cumhurbaşkanlığı Yıllık Programı.

Toda, H. Y.; Yamamoto, T., (1995), Statistical Inference in Vector Autoregression with Possibly Integrated Processes, Journal of Econometrics, 66:225-250.

Tunç H. Ve Kaya M. (2016). Türkiye'de Lojistik Sektörünün Gelişmesinde Dış Ticaretin Rolü Üzerine Bir Nedensellik Analizi, Süleyman Demirel Üniversitesi Vizyoner Dergisi, 7(14):58-65.

Tunç, H. ve Kaya, M. (2016), Türkiye'de Lojistik Sektörünün Gelişmesinde Dış Ticaretin Rolü Üzerine Bir Nedensellik Analizi, Visionary EJournal/Vizyoner Dergisi, 7(14).

Wang, L. (2005). International Trade and Modern Logistics, Finance Teaching and Research, Vol.1, 30-31.

Yang, C.C. (2008). Relationships Between International Trade and International Logistics in China", International Business, Vol.1.8-16.

Zhang, B.Y. (2009). A Study on the Influence of Logistics on the Import and Export Trade in China", Journal of International Trade, Vol.1.9-18.

Zhaofang, C. ve Qiang, W. (2010). "Air Logistics and International Trade: Evidence from China”, Journal of International Trade, 36(5), 19-24. 